\title{
Gender differences in sex-related alcohol expectancies in young adults from a peri-urban area in Lima, Peru
}

\author{
Juan A. Gálvez-Buccollini, ${ }^{1}$ Valerie A. Paz-Soldán, ${ }^{2}$ Phabiola M. Herrera, ${ }^{1}$ \\ Suzanne DeLea, ${ }^{3}$ and Robert H. Gilman ${ }^{1,4}$
}

Suggested citation Gálvez-Buccollini JA, Paz-Soldán VA, Herrera PM, DeLea S, Gilman RH. Gender differences in sexrelated alcohol expectancies in young adults from a peri-urban area in Lima, Peru. Rev Panam Salud Publica. 2009;25(6):499-505.

ABSTRACT Objectives. To estimate the effect of sex-related alcohol expectancies (SRAE) on hazardous drinking prevalence and examine gender differences in reporting SRAE.

Methods. Trained research assistants administered part of a questionnaire to 393 men and 400 women between 18 and 30 years old from a peri-urban shantytown in Lima, Peru. The remaining questions were self-administered. Two measuring instruments-one testing for hazardous drinking and one for SRAE-were used. Multivariate data analysis was performed using logistic regression.

Results. Based on odds ratios adjusted for socio-demographic variables (age, marital status, education, and employment status) $(\mathrm{n}=793)$, men with one or two SRAE and men with three or more SRAE were 2.3 (95\% confidence interval $(C I)=1.4-3.8 ; \mathrm{p}=0.001)$ and $3.9(95 \%$ $C I=2.1-7.3 ; \mathrm{p}<0.001)$ times more likely than men with no $S R A E$, respectively, to be hazardous drinkers. Reporting of SRAE was significantly higher in men versus women.

Conclusion. In a shantytown in Lima, SRAE is associated with hazardous drinking among men, but not among women, and reporting of SRAE differs by gender.

Key words Alcoholism, drinking behavior, sexual behavior, Peru.

Alcohol is the most common social drug and is responsible for most cases of addiction, as well as morbidity and mortality, compared to other addictive sub-

\footnotetext{
Asociación Benéfica PRISMA, Lima, Peru. Send correspondence and reprint requests to: Juan $A$. Gálvez-Buccollini, A.B. PRISMA, Carlos Gonzales 251, Lima 32, Peru; telephone: +51-1-464.0221; fax: +51-1-464.0781; e-mail: galvezbuccollini@yahoo.com

2 Tulane University School of Public Health and Tropical Medicine, New Orleans, Louisiana, United States of America.

3 School of Medicine, University of New Mexico, Albuquerque, New Mexico, United States of America.

4 Department of International Health, Bloomberg School of Public Health, Johns Hopkins University, Baltimore, Maryland, United States of America.
}

stances. In Peru, the average age of alcohol initiation is 17 years, and $90 \%$ of individuals between 12 and 64 years old living in urban areas have consumed alcohol at least once. Alcohol consumption occurs most frequently on weekends during social gatherings and on holidays. Moreover, 35\% of 19-29 year olds consume alcohol at least once a week and are thus considered the group at highest risk for hazardous drinking (1).

The term "expectancies" related to the use of alcohol refers to beliefs about the physiological and behavioral effects associated with its use (2). The development of alcohol expectancies usually be- gins as a series of global, diffuse, and undifferentiated beliefs, which tend to increase with age, experience with alcohol, and exposure to alcohol in social events, whether with friends or family. Due to the multifactorial nature of the beliefs on which individual expectancies are based, alcohol expectancies differ by gender, race, and culture (3).

In recent years, the role of expectancies has gained prominence in psychosocial models designed to explain alcohol use, based on evidence that individuals' early experiences with alcohol affect their future decisions regarding consumption $(3,4)$. People's beliefs on how alcohol 
affects their behavior, mood, and emotions have been correlated to adolescents' and adults' consumption patterns and tendencies. Moreover, etiologic processes that lead to risky consumption habits differ between men and women. Expectancies affect men and women differently, but these differences have been hard to isolate (4-6). Some studies have found that women might have more positive expectancies of alcohol: namely, compared to men, they have a higher expectancy of an improvement in social interactions, stress and anxiety reduction, and sexual enhancement associated with alcohol consumption (7-9). Other studies found that sex-related alcohol expectancies (SRAE) are more common among men (10). More recent studies found that gender differences do not exist in SRAE (11). Understanding gender differences in SRAE is particularly important in this era of HIV / AIDS, due to the association between hazardous drinking and risky sexual behaviors, especially among young people (12-14). For example, some studies have found that people with SRAE perceive less risk associated with unprotected sex than those without SRAE $(4,14)$.

There are two important limitations in the study of expectancies associated with alcohol consumption. First, most studies have been conducted in Western Europe or the United States; studies in developing countries are scarce and are limited to select populations (for example, among university students) (10). Second, considering the important role of culture, society, and families in the formation of individuals' expectancies, it is most likely that different alcohol expectancies would be observed in different social levels and geographic locations. Thus, culturally accepted practices in Latin America, such as machismo (an exaggerated sense of masculinity stressing domination of women, etc.) might modify the association between expectancies and alcohol-related behaviors. For example, machismo might reduce a woman's desire to consume alcohol because it is considered socially unacceptable for her to enjoy her sexuality, and alcohol consumption is associated with enjoying one's sexuality (15). The objectives of this study are therefore to estimate the effect of SRAE on hazardous drinking among young adults, and to examine gender differences in reporting SRAE, in a peri-urban population of Lima, Peru.

\section{MATERIALS AND METHODS}

\section{Study site}

The study took place in 2005 in Las Pampas de San Juan de Miraflores (PSJM), a peri-urban shantytown in Lima, Peru, with an estimated population of 40000 . As in many other shantytowns around Lima, PSJM was formed 20 years ago by immigrants from the Peruvian highlands who settled and later claimed unused land on the outskirts of Lima. Although many residents of PSIM were born and initially raised outside of Lima, most young adults living there now grew up in Lima, and Spanish is their first language. The stable employment rate in PSJM is low $(25 \%)$ and the poverty level is very high, with an annual estimated income of \$2 100 in the year 2000 (16). Diverse epidemiologic studies have been conducted in PSJM since 1986. As a result, the PSJM community has been under surveillance by physicians, public health care workers, nurses, and social workers from a local Peruvian nonprofit organization known as A.B. PRISMA (Asociación Benéfica Proyectos en Informática, Salud, Medicina, y Agricultura) for many years $(16,17)$.

\section{Sample}

The study targeted young adults between 18 and 30 years old because this age group typically has the highest rate of alcohol use (1). All PSJM residents had been registered during a census completed for previous epidemiological studies by A.B. PRISMA. Young adult residents of the shantytown between the ages of 18 and 30 were randomly selected from this census and asked to participate in the study. A computer program generated a random sample from the census list to select potential enrollees. A total of 508 men and 460 women between the ages of 18 and 30 were contacted to participate in the study by trained health promoters who made a maximum of three visits to potential participants' homes. Of these, 16 refused to participate (11 men and 5 women), and 152 were unavailable for interviews (97 men and 55 women). Seven male participants were excluded from the data analysis due to incomplete questionnaires. Thus, the total sample size was 793 subjects $(81.9 \%$ response rate): 393 men and 400 women. Additional information from subjects who did not consent to participate or were unavailable to be interviewed was not collected.

\section{Design}

Health promoters with medical research experience in the community visited the homes of the randomly selected study pool up to three times to invite eligible participants to enroll in the study. Although some of the older adults in the community may have been native speakers of a language other than Spanish, due to the large proportion of original inhabitants who emigrated from the Peruvian highlands, all of the younger adults in the study pool were Spanish-speaking or bilingual. All of the health promoters were fluent Spanish speakers and conducted the interviews in Spanish. After reviewing the study's objectives, risks, and benefits, written consent was obtained from the subjects, who agreed to participate voluntarily. To increase the instruments' reliability, interviewers completed a month-long training course that included role-playing and mock interviews. The cross-sectional study had two parts: an interview administered by the health promoters that lasted approximately 25 minutes, and a self-administered questionnaire that lasted approximately 15 minutes.

The study was reviewed and approved by the A.B. PRISMA Institutional Review Board for protection of human subjects in research.

\section{Instruments}

The questionnaire included sections on demographic characteristics, drinking habits, and expectancies about alcohol effects. However, only the questions relevant to the analysis are described here.

Socio-demographic characteristics. Standard measurements were included, such as gender, age, marital status, employment status, and education.

Drinking habits for past year. This section's questions were based on the Alcohol Use Disorder Identification Test (AUDIT). This instrument was designed by the World Health Organization (WHO) to help identify persons who might benefit from the reduction or abandonment of alcohol consumption (18). The AUDIT is easy to apply and has 
shown a high rate of sensitivity and specificity in different settings (18). Hazardous drinking is defined as alcohol consumption that confers risk of physical or psychological harm to the drinker or those around him/her (18). The AUDIT differs from other instruments for evaluation of problems related to alcohol consumption because it defines hazardous drinking operationally. Out of a maximum score of 40 points, the cut-off point for being considered a hazardous drinker is eight points for both men and women, as described in the WHO manual (18). Though some may argue that the cut-off for women should be reduced to six in order to increase sensitivity (19), this study applied the eight-point cut-off for both men and women, based on the methodology of the WHO manual and other research $(18,20)$. The study also examined the results with a six-point cutoff for women, and the results were the same. This variable was then coded in the study as binary, and participants with a score of eight or more were considered hazardous drinkers.

Sex-related alcohol expectancies (SRAE). Seven items associated with expectancies of sexual enhancement were drawn from the Alcohol Expectancy Questionnaire (AEQ): "I often feel sexier after I have had a couple of drinks," "I am a better lover after a few drinks," "Women can have orgasms more easily if they have been drinking," "I enjoy having sex more if I have had some alcohol," "I am more romantic when I drink," "I feel more masculine after a few drinks," and "After a few drinks, I am more sexually responsive" $^{\prime \prime}(21,22)$.

The versions of the AUDIT and SRAE used in this study were obtained from Babor et al. and O'Hare $(18,21)$. A Spanish version of the AUDIT instrument was available from $\mathrm{WHO}$, and the SRAE instrument was translated into Spanish by members of the current study's research team. Both instruments were then reviewed and adapted by a team of Peruvian mental health experts on this topic. The adapted instruments were then field-tested among male and female shantytown residents to ensure an adequate measurement of the variables. The entire questionnaire, including both instruments, was then pilot-tested with 100 residents of the shantytown. After the pilot test, final revisions to the instruments were incorporated, focusing on clarity, ease of understanding of the questions, and ease of application. Both the AUDIT and SRAE subscales showed an adequate internal consistency in this study, with a Cronbach's alpha score of 0.8 and 0.7 , respectively.

\section{Data analysis}

After the descriptive analysis was completed, associations between categorical variables were estimated using the chi-squared test. Comparisons of means were done using the student's ttest or the Kruskal-Wallis test. Finally, multiple logistic regression techniques were used to estimate the association between SRAE and the levels of hazardous drinking observed in both men and women. Adjustments were then taken for possible confounding variables such as socio-demographic characteristics. The results of these analyses are presented in the form of odds ratios (OR), using 95\% confidence intervals (CI); $p$ values are presented as an aid to interpretation. All analyses were done using STATA 8.0 (StataCorp LP, College Station, TX, USA).

\section{RESULTS}

\section{Sample characteristics}

The demographic characteristics of the young adults that participated in the study are outlined in Table 1 . The sample was composed of a similar number of men and women $(49.6 \%$ vs. $50.4 \%$, respectively). There were no significant age differences between men and women (men $22.3 \pm 3.2$, women $22.4 \pm 3.3$; $p=0.694)$. However, there were differences in marital status, education, and employment status: $34.0 \%$ of women were married or cohabitants compared to $16.0 \%$ of men, and $45.5 \%$ of women reported having more than a high school education compared to $30.5 \%$ of men. However, the proportion of unemployed women was two times higher than the proportion of men. With regard to classification as hazardous drinkers, the men's proportion was six times higher than the women's (see Table 1).

\section{Gender differences in reporting SRAE}

The proportion of men with one or more SRAE was higher than that of women (55.2\% vs. $38.2 \%)$. All SRAE eval- uated were reported more commonly among men than in women, and the differences were statistically significant in three of them: "I often feel sexier after I have had a couple of drinks" (men $13.0 \%$, women $8.5 \%$; $p=0.04)$; "Women can have orgasms more easily if they have been drinking" (men $27.7 \%$, women $18.5 \% ; p=0.002$ ); and "I enjoy having sex more if I have had some alcohol" (men $13.2 \%$, women $7.0 \% ; p=0.004$ ). The mean of SRAE reported overall was also higher in men than in women $(1.2 \pm 1.5$ vs. $0.9 \pm 1.5 ; p=0.0001$ ) (data not shown).

\section{SRAE effect on alcohol consumption}

In the unadjusted model, the study found that having SRAE was associated with hazardous drinking. Thus, having one or two SRAE doubled (OR $=2.4,95 \%$ $\mathrm{CI}=1.5-3.9 ; p<0.001)$ the probability of being a hazardous drinker, while having three or more SRAE quadrupled $(\mathrm{OR}=4.0,95 \% \mathrm{CI}=2.2-7.4 ; p<0.001)$ this chance among men. Among women, the study did not find any association between hazardous drinking and having one or two SRAE $(\mathrm{OR}=1.1,95 \% \mathrm{CI}=$ $0.4-3.1 ; p<0.80)$ or three or more SRAE $(\mathrm{OR}=0.4,95 \% \mathrm{CI}=0.1-2.8 ; p=0.32)$ (data not shown).

The model was then adjusted for socio-demographic variables (age, marital status, education, and employment status). There was no significant shift in the association between SRAE and hazardous drinking in the group of men or women compared with the unadjusted model, and none of the socio-demographic variables were statistically significant (Table 2).

\section{DISCUSSION}

This study reveals that an increase in SRAE is associated with increased rates of hazardous drinking in men, especially in those with a higher number of SRAE. In addition, the report of SRAE was higher in men than in women. These results suggest that, among men, the effects individuals attribute to their alcohol intake are associated with the amount of alcohol they consume.

Although some studies performed in developed countries found that SRAE had a similar effect on alcohol consumption in both men and women, other studies have found a more significant association between SRAE and alcohol 
TABLE 1. Socio-demographic characteristics, hazardous drinking, and sex-related alcohol expectancies (SRAE) of 793 young adults in a peri-urban shantytown in Lima, Peru, by gender (2005)

\begin{tabular}{|c|c|c|c|c|c|}
\hline & \multicolumn{2}{|c|}{ Men } & \multicolumn{2}{|c|}{ Women } & \multirow[b]{2}{*}{$P$-value ${ }^{a}$} \\
\hline & No. & $\%$ & No. & $\%$ & \\
\hline Sex & 393 & 49.6 & 400 & 50.4 & $N A^{b}$ \\
\hline \multicolumn{6}{|l|}{ Age (years) } \\
\hline $18-21$ & 200 & 50.9 & 184 & 46.0 & \multirow{3}{*}{0.694} \\
\hline $22-26$ & 138 & 35.1 & 152 & 38.0 & \\
\hline $27-30$ & 55 & 14.0 & 63 & 16.0 & \\
\hline \multicolumn{6}{|l|}{ Marital status } \\
\hline Single & 330 & 84.0 & 264 & 66.0 & \multirow[t]{2}{*}{$<0.001$} \\
\hline Married/cohabitant & 63 & 16.0 & 136 & 34.0 & \\
\hline \multicolumn{6}{|l|}{ Education } \\
\hline High school or less & 273 & 69.5 & 218 & 54.5 & \multirow[t]{2}{*}{$<0.001$} \\
\hline More than high school & 120 & 30.5 & 182 & 45.5 & \\
\hline \multicolumn{6}{|l|}{ Employment status } \\
\hline Employed & 329 & 83.7 & 256 & 64.0 & \multirow[t]{2}{*}{$<0.001$} \\
\hline Unemployed & 64 & 16.3 & 144 & 36.0 & \\
\hline Hazardous drinking & 129 & 32.8 & 20 & 5.0 & $<0.001$ \\
\hline \multicolumn{6}{|l|}{ Number of SRAE } \\
\hline 0 & 176 & 44.8 & 247 & 61.7 & \multirow[t]{3}{*}{$<0.001$} \\
\hline $1-2$ & 155 & 39.4 & 101 & 25.2 & \\
\hline$\geq 3$ & 62 & 15.8 & 52 & 13.0 & \\
\hline \multicolumn{6}{|l|}{ SRAE } \\
\hline I often feel sexier after I have had a couple of drinks. & 51 & 13.0 & 34 & 8.5 & 0.042 \\
\hline I am a better lover after a few drinks. & 58 & 14.8 & 52 & 13.0 & 0.474 \\
\hline Women can have orgasms more easily if they have been drinking. & 109 & 27.7 & 74 & 18.5 & 0.002 \\
\hline I enjoy having sex more if I have had some alcohol. & 52 & 13.2 & 28 & 7.0 & 0.004 \\
\hline I am more romantic when I drink. & 101 & 25.7 & 87 & 21.8 & 0.191 \\
\hline I feel more masculine/feminine after a few drinks. & 49 & 12.5 & 38 & 9.5 & 0.181 \\
\hline After a few drinks, I am more sexually responsive. & 40 & 10.2 & 38 & 9.5 & 0.749 \\
\hline
\end{tabular}

a $P$-values significant at $P<0.05$.

${ }^{\mathrm{b}} \mathrm{NA}=$ not applicable.

TABLE 2. Estimated association between sex-related alcohol expectancies (SRAE) and hazardous drinking among 793 young adults in a peri-urban shantytown in Lima, Peru (2005) a, b

\begin{tabular}{|c|c|c|c|c|c|c|c|c|}
\hline & \multicolumn{8}{|c|}{ Hazardous drinking } \\
\hline & \multicolumn{4}{|c|}{ Men } & \multicolumn{4}{|c|}{ Women } \\
\hline & \multicolumn{4}{|c|}{$(n=393)$} & \multicolumn{4}{|c|}{$(n=400)$} \\
\hline & No. & $\mathrm{AOR}^{\mathrm{c}}$ & $95 \% \mathrm{Cl}^{\mathrm{d}}$ & $P$-value ${ }^{e}$ & No. & AOR & $95 \% \mathrm{Cl}$ & $P$-value \\
\hline \multicolumn{9}{|l|}{ SRAE } \\
\hline $0^{f}$ & 37 & 1.0 & $N A^{g}$ & NA & 13 & 1.0 & NA & NA \\
\hline $1-2$ & 60 & 2.3 & $1.4-3.8$ & 0.001 & 6 & 1.2 & $0.4-3.1$ & 0.776 \\
\hline$\geq 3$ & 32 & 3.9 & $2.1-7.3$ & $<0.001$ & 1 & 0.4 & $0.1-2.8$ & 0.321 \\
\hline \multicolumn{9}{|l|}{ Age (years) } \\
\hline $18-21^{\dagger}$ & 66 & 1.0 & NA & NA & 9 & 1.0 & NA & NA \\
\hline $22-26$ & 49 & 1.1 & $0.7-1.9$ & 0.580 & 9 & 1.3 & $0.5-3.5$ & 0.583 \\
\hline $27-30$ & 14 & 1.7 & $0.3-1.4$ & 0.303 & 2 & 0.7 & $0.1-3.7$ & 0.716 \\
\hline \multicolumn{9}{|l|}{ Marital status } \\
\hline Single & 107 & 0.8 & $0.4-1.5$ & 0.503 & 15 & 1.7 & $0.5-5.2$ & 0.384 \\
\hline Married/cohabitant ${ }^{f}$ & 22 & 1.0 & NA & NA & 5 & 1.0 & NA & NA \\
\hline \multicolumn{9}{|l|}{ Education } \\
\hline High school or less ${ }^{\dagger}$ & 96 & 1.0 & NA & NA & 11 & 1.0 & NA & NA \\
\hline More than high school & 33 & 0.8 & $0.5-1.4$ & 0.539 & 9 & 0.9 & $0.3-2.3$ & 0.804 \\
\hline \multicolumn{9}{|l|}{ Employment status } \\
\hline Employed ${ }^{f}$ & 104 & 1.0 & NA & NA & 13 & 1.0 & NA & NA \\
\hline Unemployed & 25 & 1.3 & $0.7-2.4$ & 0.347 & 7 & 1.1 & $0.4-3.1$ & 0.826 \\
\hline
\end{tabular}

a Based on multiple logistic regression techniques.

${ }^{\mathrm{b}}$ Adjusted for age, marital status, education, and employment status.

${ }^{c} \mathrm{AOR}=$ adjusted odds ratio.

${ }^{d}$ Confidence interval.

e $P$-values significant at $P<0.05$.

${ }^{\dagger}$ Reference category.

g NA = not applicable. 
consumption of women (23). In the current study, an association was found between SRAE and alcohol consumption among men, but not among women, similar to the results of a study by MoraRíos and Natera in a group of Mexican university students between 17-25 years old, which found that men expected to improve their sexual performance and that of their sexual partners by drinking alcohol (10). Moreover, in the current study, among the women with the highest range of SRAE (three or more), only one woman $(1.9 \%)$ was classified as a hazardous drinker, compared to more than half $(51.6 \%)$ in the group of men with the same level of SRAE.

This finding of an association between SRAE and hazardous drinking in men but not in women in a peri-urban shantytown in Lima is consistent with the hypothesis that social and cultural differences play an important role in shaping people's behaviors. It is possible that the effect of machismo in Peru allows for men more than women to translate their SRAE into higher rates of hazardous drinking. It has been suggested that the value that a person assigns to their expectancies with alcohol would have an important role in determining hazardous drinking (2). Thus, expectancies would predict increased alcohol consumption only if the resultant effect is considered valuable or desirable by the individual. Hence, the gender role assigned to women in some Latin American contexts, in which the woman should not enjoy sex, combined with women's perception of risk of an unplanned pregnancy, might result in women considering an increase in sexuality a particularly undesirable outcome of alcohol use (15). Furthermore, considering that expectancies are modified by the actual experience of using alcohol, it is possible that SRAE have a higher effect in younger groups, who have less experience in alcohol use than older groups (24). Thus, a new drinker can be influenced by the "power" of the alcohol, while the experienced drinker drinks for other reasons or understands the true consequences of alcohol on sexual performance (i.e., deterioration of sexual function).

The definition of social behaviors as "male" or "female" is shaped by cultural, religious, and political beliefs associated with gender roles in society (25). Society creates certain interpreta- tions and norms, and individuals internalize (and often reify) these norms. Although the concept of machismo is associated with some positive values in the Latin American context, such as responsibility, strong ethical principles, and being a good provider (26), it is also associated, in many settings, with men's active subjugation of women and performance of high-risk activities to prove their "masculinity," such as heavy drinking $(26,27)$. Despite shifts in these gender roles and in the power structures within them over the past few decades, especially in regard to the workplace, traditional interpretations still play an important role in decision-making processes for men and women (28). For example, in PSJM, the influence of Catholicism, cultural interpretations of "motherhood" and "femininity," and/or a low level of acculturation to urban social mores (vs. those of the Peruvian highlands, the point of origin of most PSJM families) could make it less likely for women to use alcohol without restraint $(15,25,29)$, along with various social and economic factors (e.g., many of the changes in gender roles that have occurred in recent decades are limited to certain subpopulations, such as people with more access to education and/or high socioeconomic status) $(30,31)$. Different socioeconomic contexts (e.g., education and employment levels, and male vs. female employment) can also influence how "masculinity" and "femininity" are redefined (32). Therefore, while marital status, education, and employment status were not associated with hazardous drinking among men and women in this study, it is possible that the fairly homogenous background of the sample made it difficult to tease out the effect of these variables. Nonetheless, it should be noted that despite women's higher levels of education in the study sample, they still had lower levels of employment compared to men.

Another reason to study gender differences in SRAE is its possible association with sexual abuse (23). Some studies have reported that a high percentage of those who have committed sexual abuse had been under the influence of alcohol at the time (33). A possible hypothesis is that alcohol consumption can be interpreted in different ways depending on personal expectancies. For example, one person might view alcohol consumption on a date as an invitation to sexual contact, while another might drink to relax, or to increase his/her social interaction. Gender differences in SRAE may lead men to incorrectly assume that women are drinking to increase their sexual disinhibition, thus increasing the risk of an unwanted sexual contact (34). These hypotheses are consistent with the fact that men presented a higher number of SRAE than women in the current study, and that the most frequent SRAE among men was that "women can have orgasms more easily if they have been drinking." Therefore, more studies are needed to clarify the role that SRAE play in sexual abuse, especially unwanted sexual contact in social situations, such as "date rape" (sexual assault of a woman by a man with whom she is acquainted).

Several of the more important study limitations merit attention. First, the endogenous relationship between SRAE and hazardous drinking, which can create bias, was not taken into account. For example, the fact that men generally have higher rates of alcohol consumption compared to women (23) likely influences the observed gender difference in regard to these variables. In other words, the higher level of SRAE in groups with increased alcohol consumption, such as men, may merely reflect the influence of consumption patterns. Second, the cross-sectional and retrospective design of the study did not allow for the establishment of a cause-effect relationship between SRAE and hazardous drinking. However, it is conceptually probable that the expectancies preceded and predicted hazardous drinking, especially among young people, who have less experience with alcohol and sex. Third, the study sample only included young adults in a poor peri-urban area of Latin America, so the study results cannot be extrapolated to populations in other regions, or populations of different socioeconomic status. Fourth, the information was self-reported, and therefore might be subject to recall bias or a reporting bias complicated by social desirability. It should be noted, however, that alcohol is the most consumed social drug in Peru, and its use is easily reported because its consumption is legal and not stigmatized, as may be the case with other drugs (1). Finally, this study did not examine the role or influence of peers or social networks that may func- 
tion as facilitators or protective factors in alcohol use and may thus help clarify the dynamic between alcohol use and SRAE.

Regardless of these limitations, this study reveals the importance of SRAE as a potential determinant of hazardous drinking among men. Expectancies are potentially modifiable through diverse interventions that focus on preventing not only hazardous drinking but also risky sexual behaviors or sexual abuse. Nonetheless, it is necessary to take gender differences into account in order to develop more effective and targeted interventions. Individual interventions using cognitive restructuring and similar techniques, directed at modifying the belief that alcohol increases sexual behavior, have been found to be effective (35). Also, media campaigns directed at the community to prevent hazardous drinking (or simply regulating the advertising that directly associates alcohol consumption with sexual situations) might be effective. Future research should focus on the causal mechanisms of the association between expectancies and hazardous drinking and on the effectiveness of interventions designed to reduce this association.
Acknowledgments. The research on which this article was based was supported by grants from the PeruvianBelgium Cooperation, the National Institute of Drug Abuse (NIDA D43 TW05819), and the National Institutes of Health (NIH R01 DK63041 and NIH T35 AI07646), and by the Ellison Medical Foundation. The authors wish to acknowledge the contribution of Lilia Cabrera, Lauren Nussbaum, Guido Mazzotti, Bernardo Guimas, and Fabian Fiestas to the development of this project and publication.
1. Comisión Nacional para el Desarrollo y Vida sin Drogas (PE). II Encuesta Nacional de Prevención y Consumo de Drogas, 2002. Lima: DEVIDA; 2002.

2. George WH, Stoner SA. Understanding acute alcohol effects on sexual behavior. Annu Rev Sex Res. 2000;11:92-124.

3. Goldman MS. The alcohol expectancy concept: applications to assessment, prevention, and treatment of alcohol abuse. Appl Prev Psychol. 1994;3(3):131-44.

4. O'Hare T. Risky sex and drinking contexts in freshman first offenders. Addict Behav. 2005; 30(3):585-8.

5. Maisto SA, Carey MP, Carey KB, Gordon CM, Schum JL. Effects of alcohol and expectancies on HIV-related risk perception and behavioral skills in heterosexual women. Exp Clin Psychopharmacol. 2004;12(4):288-97.

6. Read JP, Wood MD, Lejuez CW, Palfai TP, Slack M. Gender, alcohol consumption, and differing alcohol expectancy dimensions in college drinkers. Exp Clin Psychopharmacol. 2004;12(4):298-308.

7. Rohsenow DJ, Bachorowski JA. Effects of alcohol and expectancies on verbal aggression in men and women. J Abnorm Psychol. 1984; 93(4):418-32.

8. Abrams DB, Wilson GT. Effects of alcohol on social anxiety in women: cognitive versus physiological processes. J Abnorm Psychol. 1979;88(2):161-73.

9. Hull JG, Bond CF Jr. Social and behavioral consequences of alcohol consumption and expectancy: a meta-analysis. Psychol Bull. 1986; 99(3):347-60.

10. Mora-Ríos J, Natera G. Expectativas, consumo de alcohol y problemas asociados en estudiantes universitarios de la ciudad de México. Salud Publica Mex. 2001;43(2):89-96.

11. Leigh BC. The relationship of sex-related alcohol expectancies to alcohol consumption and sexual behavior. Br J Addict. 1990;85(7):919-28.

12. Gálvez-Buccollini JA, Paz-Soldán V, Herrera P, DeLea S, Gilman RH, Anthony JC. Links between sex-related expectations about alcohol, heavy episodic drinking and sexual risk among young men in a shantytown in Lima, Peru. Int Fam Plan Perspect. 2008;34(1):15-20.

13. Dermen KH, Cooper ML, Agocha VB. Sex-related alcohol expectancies as moderators of

\section{REFERENCES}

the relationship between alcohol use and risky sex in adolescents. J Stud Alcohol. 1998; 59(1):71-7.

14. Fromme K, D'Amico EJ, Katz EC. Intoxicated sexual risk taking: an expectancy or cognitive impairment explanation? J Stud Alcohol. 1999; 60(1):54-63.

15. Yamamoto J, Silva JA, Sasao T, Wang C, Nguyen L. Alcoholism in Peru. Am J Psychiatry. 1993;150(7):1059-62.

16. Saito M, Bautista CT, Gilman RH, Bowering A, Levy MZ, Evans CA. The value of counting BCG scars for interpretation of tuberculin skin tests in a tuberculosis hyperendemic shantytown, Peru. Int J Tuberc Lung Dis. 2004; 8(7):842-7.

17. Berkman DS, Lescano AG, Gilman RH, Lopez SL, Black MM. Effects of stunting, diarrhoeal disease, and parasitic infection during infancy on cognition in late childhood: a followup study. Lancet. 2002;359(9306):564-71.

18. Babor TF, de la Fuente JR, Saunders J, Grant M. The Alcohol Use Disorder Identification Test: guidelines for use in primary care. 2nd ed. Geneva: World Health Organization; 2001.

19. Rubio G, Bermejo J, Caballero MC, Santo Domingo J. Validación de la prueba para la identificación de trastornos por uso de alcohol (AUDIT) en atención primaria. Rev Clin Esp. 1998;198(1):11-4.

20. Mazzotti G, Ordoñez C, Bustamante I, Acosta $\mathrm{R}$, Contreras C, Gallo C, et al. Consumo de alcohol y otras sustancias psicoactivas en pacientes atendidos en un servicio de emergencia de Lima-Perú. Rev Per Drogodep. 2006; 4(1):115-35.

21. O'Hare T. Drinking and risky sexual behavior in young women and men: a covalidation study. J Alcohol Drug Educ. 1998;43(3): 66-77.

22. Brown SA, Christiansen BA, Goldman MS. The Alcohol Expectancy Questionnaire: an instrument for the assessment of adolescent and adult alcohol expectancies. J Stud Alcohol. 1987;48(5):483-91.

23. Rauch SA, Bryant JB. Gender and context differences in alcohol expectancies. J Soc Psychol. 2000;140(2):240-53.

24. Leigh BC, Stacy AW. Alcohol expectancies and drinking in different age groups. Addiction. 2004;99(2):215-27.
25. Ahrold TK, Meston CM. Ethnic differences in sexual attitudes of U.S. college students: gender, acculturation, and religiosity factors. Arc Sex Behav. Epub 2008 Oct 7.

26. Galanti GA. The Hispanic family and malefemale relationships: an overview. J Transcult Nurs. 2003;14(3):180-5.

27. Beck KH, Bargman CJ. Investigating Hispanic adolescent involvement with alcohol: a focus group interview approach. Health Educ Res. 1993;8(2):151-8.

28. Lyons AC, Dalton SI, Hoy A. 'Hardcore drinking': portrayals of alcohol consumption in young women's and men's magazines. J Health Psychol. 2006;11(2):223-32.

29. Seale JP, Shellenberger S, Rodriguez C, Seale JD, Alvarado M. Alcohol use and cultural change in an indigenous population: a case study from Venezuela. Alcohol Alcohol. 2002 37(6):603-8.

30. Forje CL. Economic crisis helps to "demarginalize" women. Dev Pract. 1998;8(2):211-6.

31. Gallardo-Hernández G, Ortiz-Hernández L, Compeán-Dardón S, Verde-Flota E, DelgadoSánchez G, Tamez-González S. La intersección entre el género y el estrato socioeconómico en la elección de profesión del área de la salud. Gac Med Mex. 2006;142(6): 467-76.

32. Tiano S, Ladino C. Dating, mating, and motherhood: identity construction among Mexican maquila workers. Environ Plan A. 1999;31(2): 305-25.

33. Lehrer JA, Lehrer VL, Lehrer EL, Oyarzún PB. Prevalence of and risk factors for sexual victimization in college women in Chile. Int Fam Plan Perspect. 2007;33(4):168-75.

34. Gross AM, Bennett T, Sloan L, Marx BP, Juergens J. The impact of alcohol and alcohol expectancies on male perception of female sexual arousal in a date rape analog. Exp Clin Psychopharmacol. 2001;9(4):380-8.

35. Wiers RW, Kummeling RH. An experimental test of an alcohol expectancy challenge in mixed gender groups of young heavy drinkers. Addict Behav. 2004;29(1):215-20.

Manuscript received on 8 May 2008. Revised version accepted for publication on 18 November 2008 . 
RESUMEN Objetivos. Estimar el efecto de las expectativas generadas por el consumo de alcohol relacionadas con el sexo (SRAE) sobre la prevalencia del consumo peligroso y analizar las diferencias en la información sobre las SRAE según el género.

Diferencias de género en Métodos. Asistentes entrenados aplicaron parte de un cuestionario a 393 hombres y las expectativas generadas 400 mujeres de 18 a 30 años de edad residentes en un barrio marginal periurbano de por el consumo de alcohol relacionadas con el sexo en adultos jóvenes de la periferia Lima, Perú. Los participantes respondieron las preguntas restantes de forma individual. Se emplearon dos instrumentos de evaluación: uno sobre el consumo peligroso y otro sobre las SRAE. Se realizó un análisis multifactorial de los datos mediante regresión logística.

urbana de Lima, Perú

Resultados. Según las razones de posibilidades (odds ratios) ajustadas por algunas variables sociodemográficas (edad, estado marital, educación y situación laboral) ( $n=$ 793), los hombres con una o dos SRAE y los que tenían tres SRAE o más presentaron 2,3 (intervalo de confianza de 95\% [IC95\%]: 1,4 a 3,8; $P=0,001$ ) y 3,9 (IC95\%: 2,1 a 7,3; $P<0,001)$ veces más probabilidades, respectivamente, de ser bebedores peligrosos que los hombres sin SRAE. Los hombres informaron SRAE en una proporción significativamente mayor que las mujeres.

Conclusiones. En un barrio periférico pobre de Lima, las SRAE se asociaron significativamente con el consumo peligroso de bebidas alcohólicas en hombres, pero no en mujeres, y se observaron diferencias en la información sobre las SRAE según el género.

Palabras clave Alcoholismo, consumo de bebidas alcohólicas, conducta sexual, Perú. 